\title{
Design and Fabrication of Low Cost Automatic Cleaning Module for Solar PV Systems
}

\author{
Vijayakumar K., Santhosh Ram G. P., Abubakkar siddhik M., Parameswari A. M.
}

\begin{abstract}
The Solar PV modules are usually engaged in dusty environments which are the condition in many tropical countries like India. The dirt gets hoarded on the superficial of the PV module and chunks the photons from the sun. It decreases the generation ability of the $P V$ module. The power output decreases the efficiency, if the PV module is not cleaned for a long time. In order to habitually clean the dust, an automatic cleaning system has been proposed, which senses the light energy from the sun on the solar panel and also cleans the PV module automatically. This system is realized with PIC16F877A microcontroller which controls the geared servo motor. This system consists of a sensor (LDR) to make it dusk to dawn. While for cleaning the PV modules, a mechanism consists of a sliding wipers has been developed. In earlier machinery, cleaning of $P V$ panels was done manually. But here the PV panels has been cleaned by automatic system i.e. wiping mechanism with water flow for effective cleaning.
\end{abstract}

Keywords: automatic cleaning, DC wiper motor, low cost, Solar panel cleaning, Solar PV panel.

\section{INTRODUCTION}

$\mathrm{T}$ he collection of dust in solar panel is a regular problem which ultimately reduces the efficiency of the panel. In the past, this has usually been done by wiping the panels manually. This operation produced a great deal of dust that is rather objectionable both from the stand point of health and cleanliness. The intension of our project is to design and develop an automatic cleaning module for solar PV systems. This technique was selected by us taking into consideration some comfort while cleaning the solar panel. This project is implemented to make human work easier and can reduce the use of manpower because of its potential applications.

This project design and development of automatic cleaning module for solar panels is cost effective as it involves only minimal hardware and mechanical setup and can clean the panels automatically with sliding type wipe mechanism and reduces the time consumed in hand cleaning. There are several aspects that disturb solar power efficiency, such as bird/pigeons droppings, shadow, temperatures, and dirt.

Revised Manuscript Received on December 15, 2019.

Vijayakumar K., Assistant Professor, Department of Electrical and Electronics Engineering, Kalasalingam Academy of Research and Education. Tamil nadu, India.

Santhosh Ram G. P., Department of Electrical and Electronics Engineering, Kalasalingam Academy of Research and Education. Tamil nadu, India.

Abubakkarsiddhik M., Department of Electrical and Electronics Engineering, Kalasalingam Academy of Research and Education. Tamil nadu, India.

Parameswari A. M., Department of Electrical and Electronics Engineering, Kalasalingam Academy of Research and Education. Tamil nadu, India.
The major issue that disturbs a PV panel's effectiveness is dust, which can decrease its efficiency by up to $50 \%$, dependent on the environs. Usually cleaning of panels is being done manually with manpower. The dust and the environment leads to several health problems like asthma, wheezing, dust allergy etc.

The competitive design is to achieve automated cleaning of the solar panel in one stroke with the motor control in forward and reverse direction and with the sensor/limit switch to stop the erasing at the edges of the panel. The module is planned with water sprinkler for effective cleaning. This system is also planned to be working with dusk to dawn technology along with solar backup itself as utility depend free system.

\section{LITERATURE REVIEW}

In literature, Alireza Gheitasi [5], established a low-cost system of automation to maintain the efficiency of solar panels connected in an array by providing cleaning on demand. Data Collection is being done by wireless Sensor networks from individual panels. Rutvij P. Kulkarni [3], developed an automated system implemented using ATMEGA 328 microcontroller. Earlier the robotic cleaning system for solar panels, can clean the glass surface of a Solar panel array at varying angles from horizontal to vertical [4]. S.B. Halbhavi [1], implemented the system using 8051 microcontroller for controlling the geared dc motor. Athira Sivan [2] implemented the system using AVR controller for detecting the LDR values and also with the help of Analog to Digital ConvDabhi Chirag et al [6], developed a Cleaning System to eliminate the dust on its surface on a fixed basis and the solar power plant output is maintained. The system is a pneumatic suction cups robotic system which is not cost effective and could move independently on the surface of solar panels.

In this project, we have implemented the automatic cleaning module with sliding type wipe mechanism, battery backups and also with water sprinkler for effective cleaning. 


\section{Design and Fabrication of Low Cost Automatic Cleaning Module for Solar PV Systems}

\section{METHODOLOGY}

The block diagram of the model is exhibited in the figure.

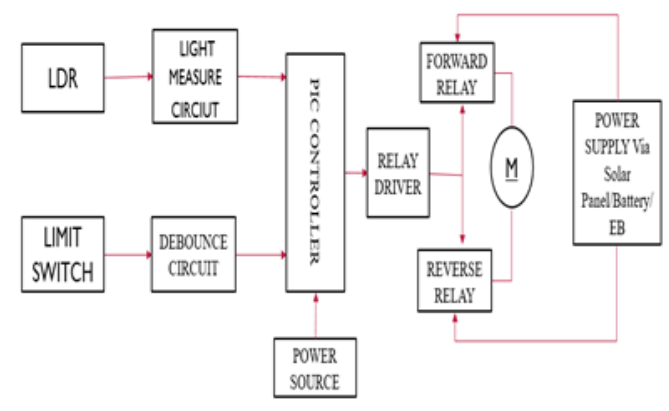

Figure1: Block Diagram of Automatic cleaning schematic

The design is able to achieve automated cleaning of the Solar panel in one stroke with the motor control in forward and reverse direction and with the sensor/limit switch to stop the erasing at the edges of the panel. The system is incorporated with Arduino controller board, motor driver L293D from Texas Instruments, motor, power supply and sensor/limit switch. As the system is planned with solar backup IC LM5175 from Texas Instruments is required for buck boost operation of the power supply from solar panel to the motor. The products used are L293D Quadruple Half-H Drivers for bi-directional motor control and LM5175 42V This work is to clean the panels automatically with sliding type wipe mechanism and reduce the hand cleaning. It is very flexible to attach with different size of solar panels. The electrical source needed to drive the DC motor and the water pump is provided from the battery which is charged by the panel.

\section{WORKING}

Usually cleaning of the panels is being done manually with manpower. The dust and the environment leads to several health problems like asthma, wheezing, dust allergy etc. The competitive design is to achieve automated cleaning of the Solar panel in one stroke with the motor control in forward and reverse direction and with the sensor/limit switch to stop the erasing at the edges of the panel. The development is planned with water sprinkler for effective cleaning. The system is planned to be working with solar backup itself as utility depend-free system promoting go green technology. In the cleaning system, the microcontroller sends command to operate the system. At the starting condition, The LDR's light measurement value will be in zeroth condition. As the light incident on the LDR, the lux value will be increased and it will reach the particular unit value, the microcontroller sends the signal to the pump for its operation to start. When the motor pump goes to ON condition, the water flows on the panel. These activities is done only at the time limit, when the water pump goes to OFF condition. After, the DC wiper motor getting started, at the first limit switch, the wiper moves to forward direction until it hitting the second limit switch. Then the wiper moves to reverse direction until it reach the first limit switch. This system will trigger to clean the PV panels. Wide Vin 4-Switch Synchronous Buck-Boost Controller.

\section{COMPONENTS}

The main components are used in our project is PIC Microcontroller, LDR, DC wiper motor, Limit switch.

PIC Microcontroller:

The PIC 16F877A is utilized in our system to control the cleaning mechanism automatically as dusk to dawn technology.

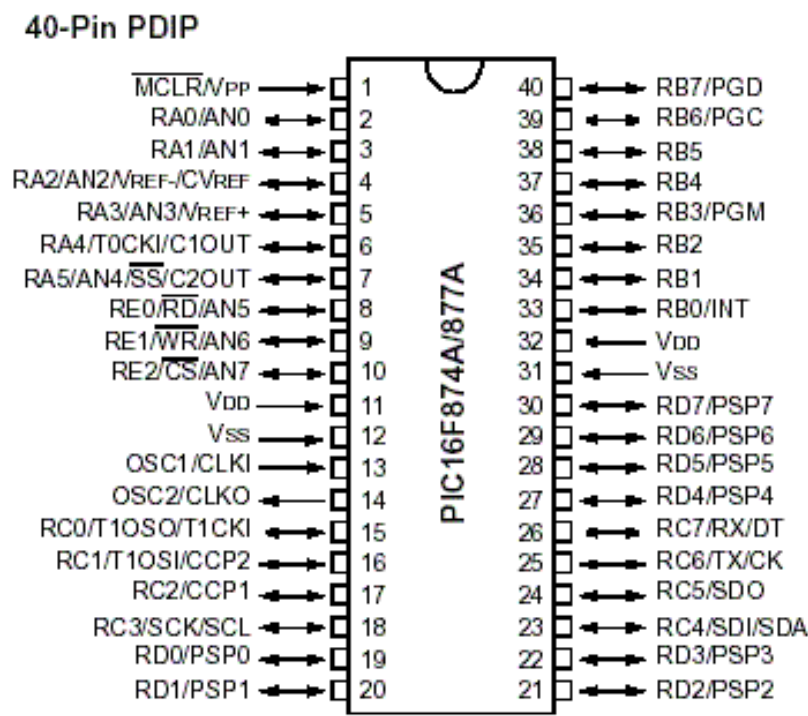

\section{LDR:}

Figure 2: Pin diagram of Microcontroller

A Light Dependent Resistor or Cadmium Sulfide cell is a resistor whose resistance decreases with increasing incident light intensity. It can also be referenced as a photoconductor.

The resistance will be very high when no light is present and is significantly lower when they are illuminated. Under normal conditions, light falls on LDR and in case of a fault the LDR will be subjected to darkness.

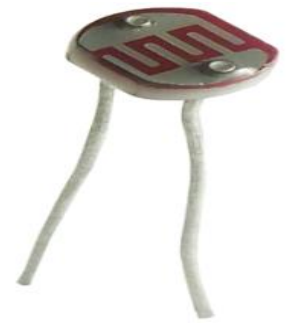

\section{Wiper Motor:}

Figure 3: Light Dependent Resistor

The geared servo motors are strategies in the wiper system that operates on a power source in order to slide the wiper brush in a smooth forward and reverse motion. The motor rotates continuously in one direction which is transformed into a reverse and forward motion.

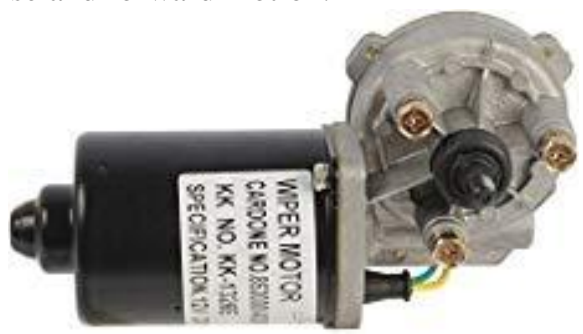

Figure 4: Wiper motor 


\section{Limit switch:}

A limit switch is a simple mechanical contact switches. It is used to drive a DC motor for gate open and close. This unit is interfaced with the micro controller to control the motion of the motor which controls the wiping mechanism at the edges of the panel.

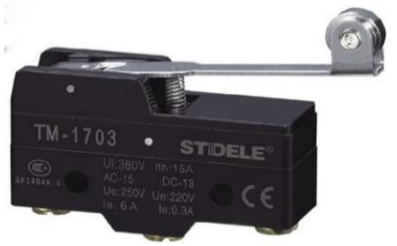

\section{Figure 5: Limit switch}

\section{LCD Display:}

LCD is mainly used for displaying the information. Here we are using 2x16 LCD. An LCD display used here displays all the information right from beginning of the operation of pump for water flow and motor wiping in the front and reverse and finally the end of the operation for the user to understand the autonomous operation of the cleaning mechanism.

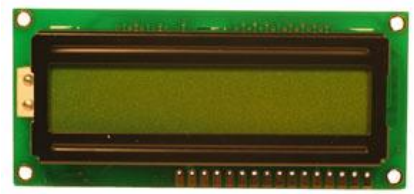

Figure 6: LCD Display

The prototype developed is presented in the following figure 7 .

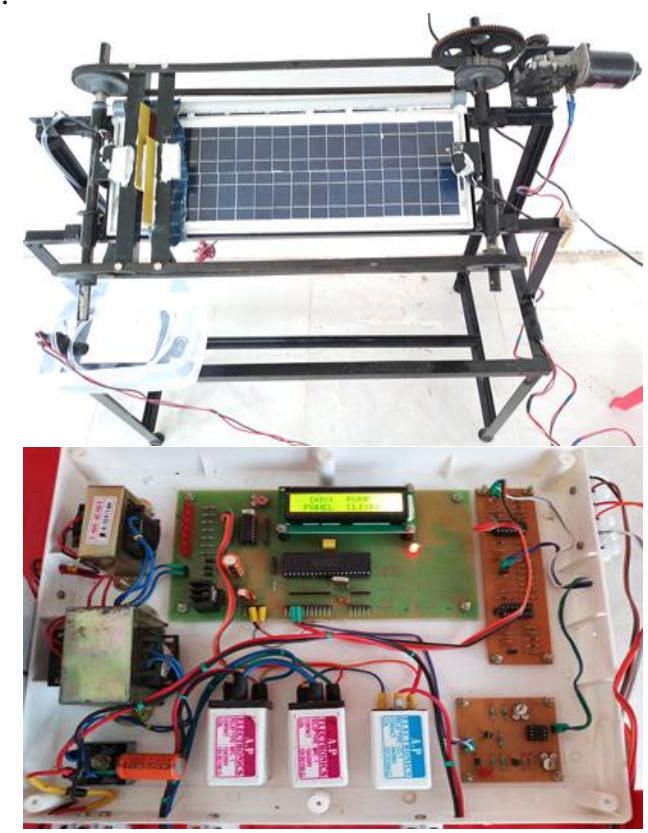

Figure 7: Solar panel cleaning prototype with controller

The following are the advantages of the system

- Cost is low

- Space utilisation is less

- Solar PV panels efficiency is increased

- PV panel life span is also increased

- Power consumption is low

- Man power is not required

- Eco friendly - Go green technology

\section{CONCLUSION}

The presented system is designed for real time use. It responds to every state conferring the program which is coded and installed into the controller for effective usage. The system is efficient to clean the solar PV panels. Due to this system, the efficiency is also increased. It is also useful in places wherever the human could not be able to reach to clean the solar PV panels. The accumulation of dust in a solar panel is a regular problem in the industry. The major factors that affect the panels are dirt, dust and bird droppings. It reduces the efficiency of the panel. Dry cleaning only remove the outer layer of the dust. But water cleaning removes all the sediment dirt in the panel. This automatic cleaning system is simple way to clean the Solar PV panels.

The innovation of our project is design and development of a low cost Smart Cleaner for Solar panels. This technique was selected by us by taking into consideration some comfort while cleaning the Solar panel. The project Design and development of Smart Cleaner for Solar panels can clean the Panel automatically with sliding type wipe mechanism and reduces the time consumed in manual cleaning. The development is planned with water sprinkler for effective cleaning. The system is planned to be working with solar backup itself as utility depend-free system promoting go green technology and improving efficiency.

\section{REFERENCES}

1. "Microcontroller Based Automatic Cleaning of Solar Panel", by S. B Halbhavi, S. G. Kulkarni, in International Journal of Latest Trends in Engineering and Technology (IJLTET).

2. "Automatic Self Cleaning Solar Panel", International Research Journal of Engineering and Technology (IRJET) e-ISSN: 2395 -0056, Volume: 04 Issue: 05 | May-2017 p-ISSN: 2395-0072.

3. "Design an Automated Cleaning System to Improve Efficiency of Photovoltaic Cells", by Shishir Kumar Das, Ankit Srivasan, and Lucky Shrivastav, SSIPMT, Raipur, Chhattisgarh, India, ISSN: 2250-0138.

4. J. B. Jawale; V. K. Karra; B. P. Patil et al, "Solar panel cleaning bot for enhancement of efficiency - an innovative approach", IEEE 3rd International Conference on Devices, Circuits and Systems (ICDCS), 3-5 March 2016.

5. Alireza Gheitasi; Ali Almaliky et al, "Development of an automatic cleaning system for photovoltaic plants", IEEE PES Asia-Pacific Power and Energy Engineering Conference (APPEEC), 15-18 Nov. 2015.

6. Dabhi Chirag et al, "Design and Development of Solar Panel Cleaning Machine", International Journal of Advance Engineering and Research Development, e-ISSN-2348-4470, P-ISSN-2348-6406, April-2017.

\section{AUTHOR PROFILE}

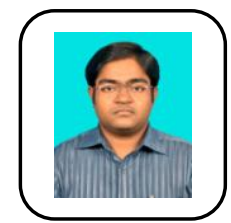

K.Vijayakumar, Assistant professor in the department of Electrical and Electronics Engineering, Kalasalingam Academy of Research and Education. He is under graduated in EEE and post graduated in Power Electronics \& Drives with 3 years industrial governing experience. 